\title{
Conceptual Modeling for Vital Power Scale for Corporate Management by Theory of Constraint
}

\author{
Hirofumi DOI ${ }^{\mathrm{a}, 1}$ and Takeshi SHINODA ${ }^{\mathrm{b}, 2}$ \\ ${ }^{a}$ Mitsui E\&S Shipbuilding Co.,ltd/ Graduate School of Engineering, Department of \\ Urban and Environmental Engineering, Kyushu University, Japan \\ ${ }^{\mathrm{b}}$ Professor, Department of Marine Systems Engineering, Kyushu University, \\ 744 Moto-oka, Nishi-ku, Fukuoka City, Japan 819-0395
}

\begin{abstract}
According with the exponential growth of Information Technology and current volatility world, the company has to drive uncertainty much rather than before. This is the time that keeping still shall result in termination of company. Therefore it is important to clarify the priority evaluation measure for continuing company operation, which we will define the vital power scale in this paper. Focusing working capital (Cash enable company to do legal payment to any stakeholders), which is essential to maintain company operation, evaluation measure for vital power of company (major measurable factor to evaluate working capital or practical measurable index for corporate management, corporate management is to enable to keep company alive) has been studied with TOC (Theory of constraints). Investigation has been done by using dice simulation having assumption of linkage and fluctuation in system, which is introduced by TOC, under the variable market price and varying company productivity.
\end{abstract}

Keywords. TOC, Lead Time, Working Capital, Cash Flow, Throughput

\section{Introduction}

Exponetial IT development called the Third Industrial Revolution and the Fourth Industrial Revolution by Aritficial Inteligence development, has been making company to change rapidly and radically. The new movement called "unbundling" can be seen frequently, which means that the current competitive potential shall loose its advantage if the company insisting the same business model or the same competitive edge. It is obviously the time that company has to change. But there still is the necessary assumption to last company under such varying economic environment. In this paper, the necessary assumptions to keep company alived, shall be clarified by TOC thinking process and further the some Index to last company alived, were investigated. Study has been done by focusing large structure manufacture industry field i.e. Shipbuilding. Regarding large structure manufacturing, the delay of delivery due to fluctuation and uncertainty occurred during manufacturing progress are often observed. The risk of uncertainity and fluctuation is quite serious issue for steady

\footnotetext{
${ }^{1}$ Corresponding Author, Email: gpspr773@yahoo.co.jp.

${ }^{2}$ Corresponding Author, Email: shinoda@nams.kyushu-u.ac.jp.
} 
company result. The study has been done on the shortening Lead Time not so as to delay due date and contribution of system capacity margin to avoid risk and realize steady cash flow.

\section{Necessary condition to continue company}

Vital Power Scale is defined by some Index that influeces the assumption for lasting company in this paper. Figure $1 \& 2$ are study on assumption to enable company operation assumption by TOC thinking process - linking matter by "cause \& effect relation". Assumption stated in Figure 1 is necessary assumption to keep company alive. If no money, company cannot hire any resource nor material. If no resources, company cannot be operated nor have any necessity to earn money. If no market, company shall have no added value and cannot earn any money. But If no skill in company, company can develope skill or buy skilled resource by investment cash as describe in Figure 2. Assumptions in Figure 1 are found as prime assumption. Figure 3 shows how cash shall move through stakeholders on shipbuilding industry, and show the existence of cash flow (circulation) is important assumption, which shall describe as shown in Figure 4 by TOC thinking process.

\subsection{The condition to continue company operation / to keep legal payment}

The condition in sufficient working capital has to be clarified. The company has to accomplish the order to the client until its due date, with steady payment to supplier and payment salary. The necessary cash to pay cash to supplier (Variable cost) and to pay salary (Fixed cost), have to be done by law. The equation (1) shows throughput, which is same as margin profit. The equation (2) shows that summation/integration of throughput and fixed cost. The constant term of surplus money is necessary to complete legal payment at any time. If this value is minus, company has to borrow additional money from financier. The equation (3) is obtained by differentiated in time. The equation (3) shows that it is necessary to obtain sufficient surplus cash in the equiation (2) by making bigger throughput obtaining velocity than fixed cost consumption velocity. [5]. If the company cannot establish the equation (3), the risk of bankruptcy of company shall be high due to decreasing surplus cash.

Where,

$$
\begin{aligned}
\mathrm{Tp} & =\mathrm{S}-\mathrm{Cv} \\
\sum \mathrm{Tp}+\text { Surpuls cash } & >\sum \mathrm{Cf} \\
\frac{\mathrm{d}}{\mathrm{dt}} \cdot \mathrm{Tp} & >\frac{\mathrm{d}}{\mathrm{dt}} \cdot \mathrm{Cf}
\end{aligned}
$$

Tp : Throughput, Margin profit

$\mathrm{Cv}$ : Variable Cost
$\mathrm{S}:$ Sales

Cf : Fixed Cost 


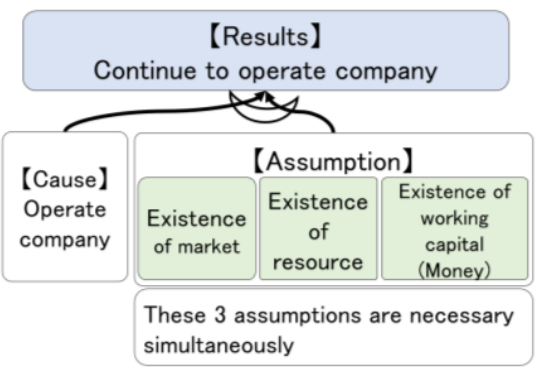

Figure 1. Fundamental condition for lasting company.

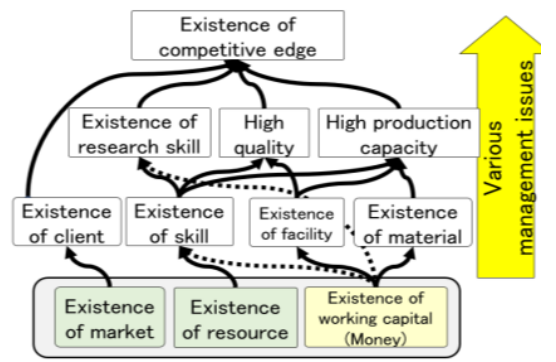

Figure 2. Verification on fundamental condition for lasting company.

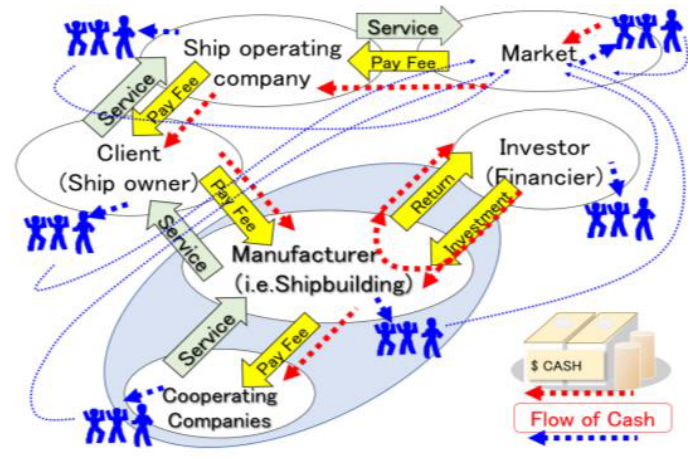

Figure 3. Cash flow observed on shipbuilding industry.

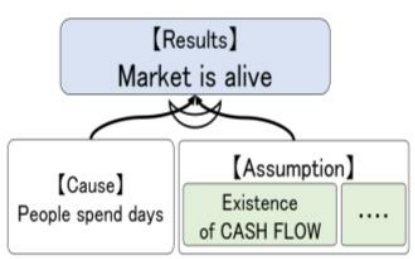

Figure 4. Cash flow as necessary assumption for existence of market.

\subsection{The way to become condition in sufficient surplus cash}

Regarding the equation (3), the fixed cost consumption velocity shall be obtained by the average salary and quantity of resources. The salary and quantity of resources are decided by the Top management with their strategy plan. The fixed cost consumption velocity is constant value until Top management might change his Will. The throughput obtaining velocity shall be decided by throughput and its production turnover rate of its constraint stage (bottle neck stage). The key value is the LT of constraint stage. The shortening LT of bottle neck is to increase working capital.

The index supported by investors is ROE (Return of Equity), which dimension is also turnover rate. ROE require the company to produce the high benefit ratio by utilizing investment. That means the steady cash flow to be produced in the market (company \& investor). ROE is common target value for company and investor.

\section{TOC improvement cycle as method of shortening LT}

TOC serves improvement cycle by focusing constraint (bottle neck). Figure 5 shows TOC improvement cycle. TOC prepare the interactive TOC improvement cycle simulation by using dice [4] . Dice simulation is simulation on random phenomenon analysis. Monte Calro simulation method is general simulation method in the academy area. Dr. Goldratt.E.M and TOC experts adopt dice as random generator, which is quite familiar to non-academy persons as random phenomenon, to explain TOC through 
playing interactive simulation. So dice simulation is adopted in this study. Figure 6 shows one result of dice simulation. Chocking inlet shall induce decreasing WIP (Work In Process) in the system and then the LT shall be obviously shortened. The bigger injection than the output shall easily increase the WIP in the system, then decrease cash in the system. The steady condition of working capital is to increase cash in the system. TOC improvement cycle is good management method for steady company operation.

\section{Logic support working capital}

Reducing WIP (Shortening LT is to minimize period of existing WIP in the system.) shall bring encashment and then the cash flow shall be improved. Furthermore shorter LT shall decrease risk of making delay due date directly, which smooth proceeding process of value added in value chain. Figure 7 shows how shortening LT induce desirable condition in future. The simulation study based on the scenario of business construction were done. To simulate general market, simulation shall include following assumptions 【1: Fluctuation in demands, 2: Fluctuation in market price, 3: Variation on productivity of each company in VC(Value Chain), 4: company is linked in VC, 5: Fluctuation in daily production of each company I

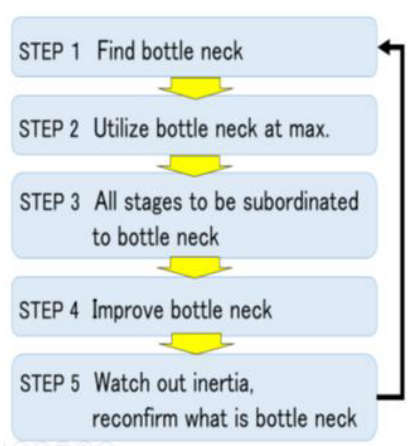

Figure 5. TOC impronement cycle.

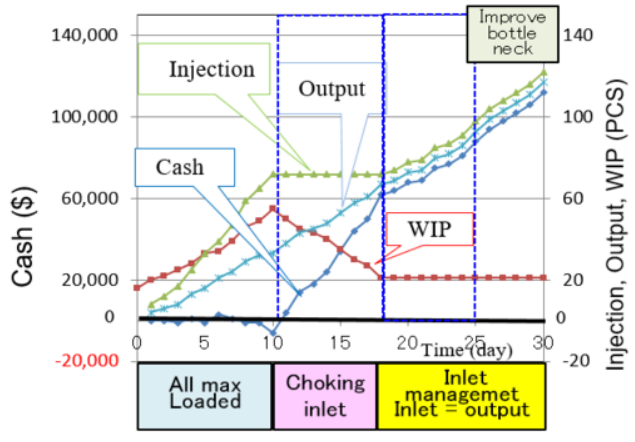

Figure 6. TOC way improvement simulation result.

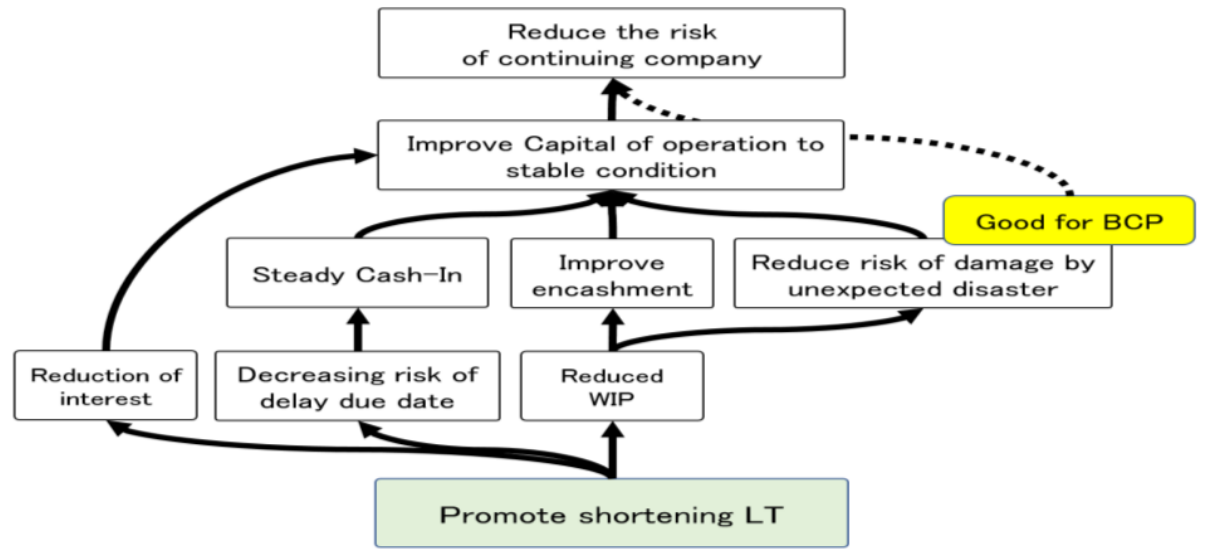

Figure 7. Analysis the effect by shortening LT. 


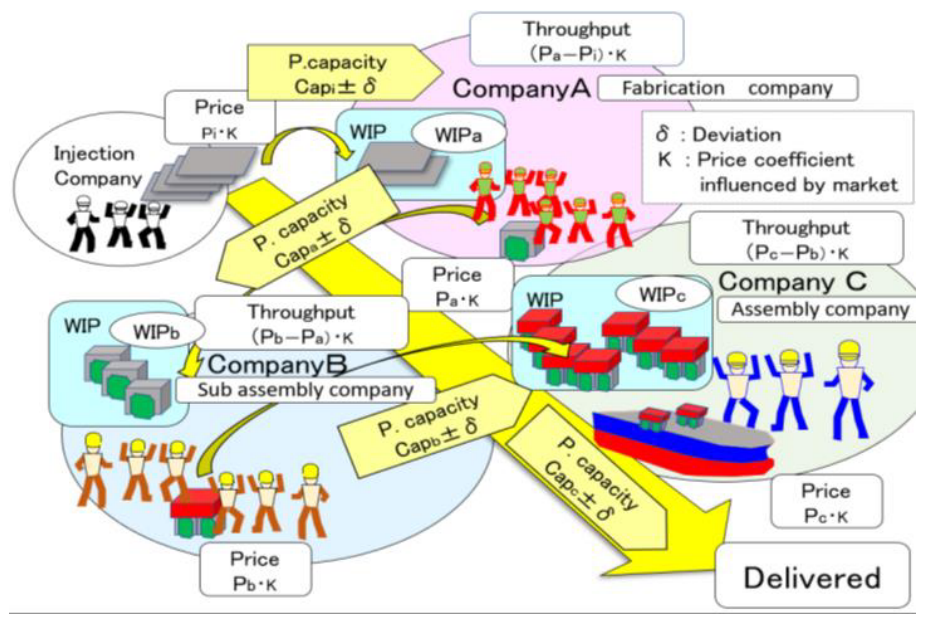

Figure 8. Simulation model diagram.

Management Index is to be of measurable and not vague value.

a) Value to be measured correctly : Cash, Amount of WIP, LT (measure time of start $\&$ finish)

b) Value to be measured not correctly : Production capacity, fluctuation of production, fluctuation of market price ratio, spent man hour on each task(it is too complex to measure precisely)

In the dice simulation, LT is calculated as estimated LT of the nearest future. The estimated LT is obtained by dividing current WIP by current production capacity, in real time.

$$
\begin{aligned}
& \mathrm{LT}=\text { WIPi } / \mathrm{PCi} \\
& \mathrm{PCi}=\text { WIPi } / \mathrm{LT}
\end{aligned}
$$

Where,

WIPi : WIP at time i

PCi : Production capacity at time i

Dimensional unit of production capacity is same as turnover rate, production capacity is the potential of production velocity.

Figure 8 shows simulation model. Variation of external environmental effect (demand \& market price) is expressed by varying market price. Internal environment effect is expressed by varying the production capacity. Figure 9 shows the varying scenario of external environment effect.

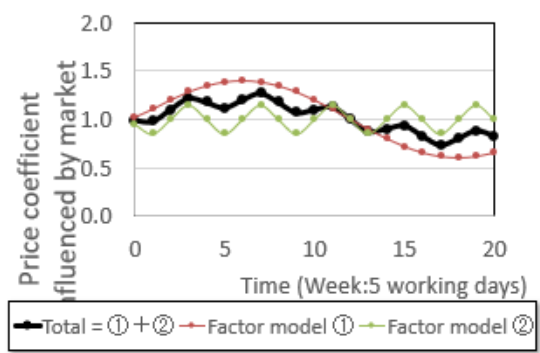

Figure 9. Effect of external environmental condition in simulation.

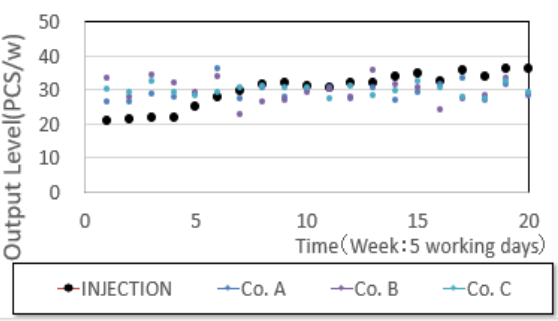

Figure 10. Scenario at beginning of business until around full desinated capacity. 

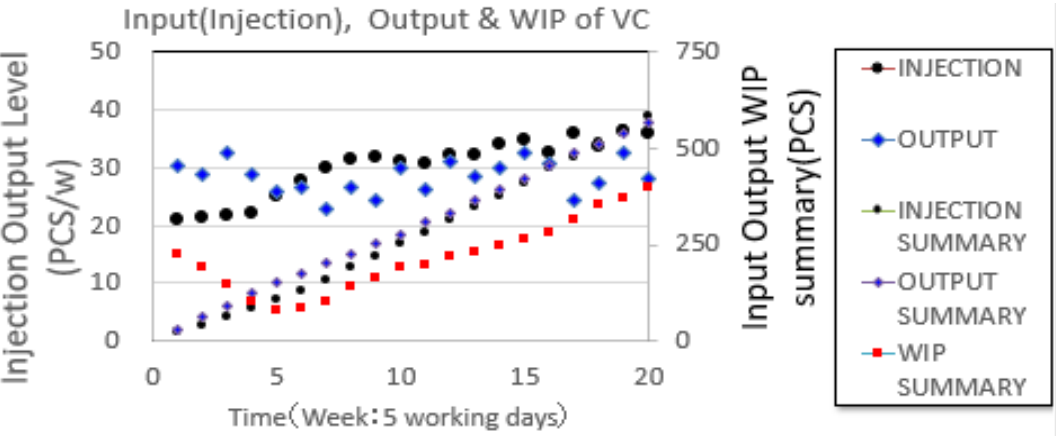

Figure 11. Simulation results (Input Output \& WIP in VC) at developing period.

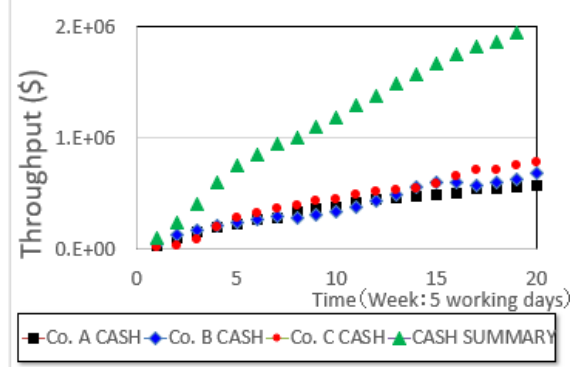

Figure 12. Simulation results (Throughput/Cash)) at developing period.

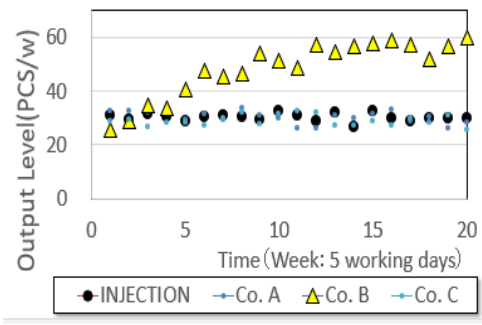

Figure 14. Scenario at 1 company(Co. B) improving capacity.

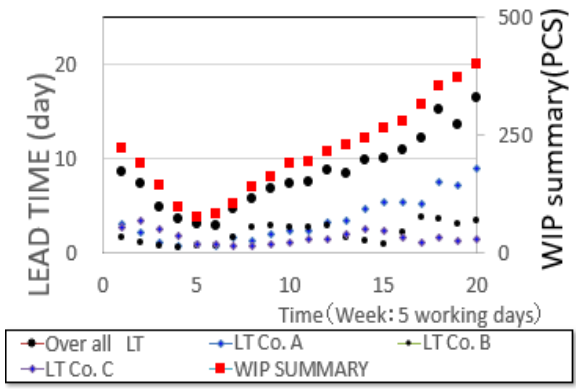

Figure 13. Simulation results (ILead time) at developing period.

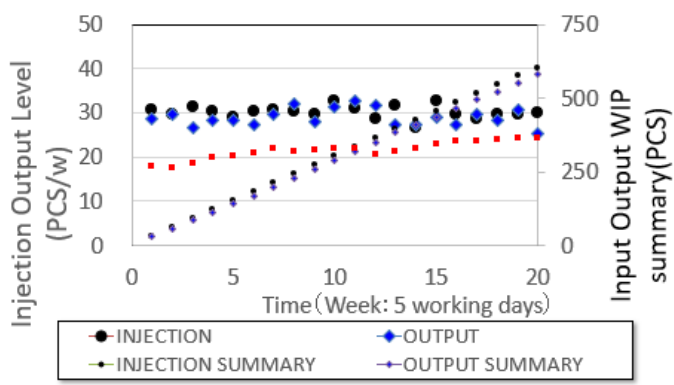

Figure 15. Simulation results (Input Output \& WIP in VC) at 1 company(Co. B) improving capacity.

Steady business proceeding might bring the period that the new order approaching over designated production capacity as shown in Figure.10. Figure 11 13 shows its results. The throughput shall be increased as increasing inlet/new order. But around same inlet as production capacity, the trend of increasing WIP in system are observed, and the throughput shall not be increased in spite of increasing injection. The increment of WIP in system shall bring in the longer LT, which might increase the risk of delay due date, there are unfavorable disturbance in the system.

Simulation study in case that one company understand the importance of LT make improving LT, was done. Figure 14-17 shows its results. The LT was decreased significantly and also throughput shall become more stable than other companies in VC. The one company LT improvement in VC shall be independent from/to other company conditions. As per the improved company efficiency, its efficiency has been worse. The improved company shall get idle due to buffer in LT. The LT improvement having idles in system shall bring the throughput improvement and increasing cash in system, 
which reduce risk in working capital. Figure 18-21 shows the results each company has improved its capacity with some phase lug. Each company has succeeded stable throughput by reducing WIP in system.

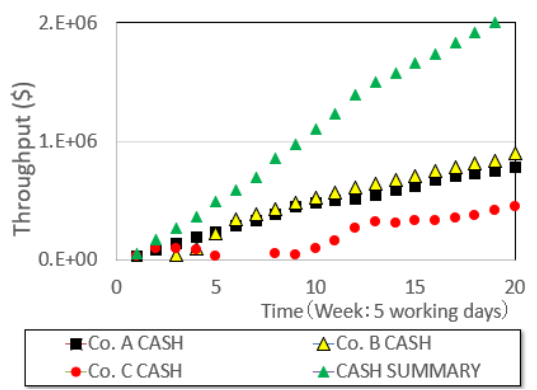

Figure 16. Simulation results (Throughpu(Cash)) at 1 company(Co. B) improving capacity.

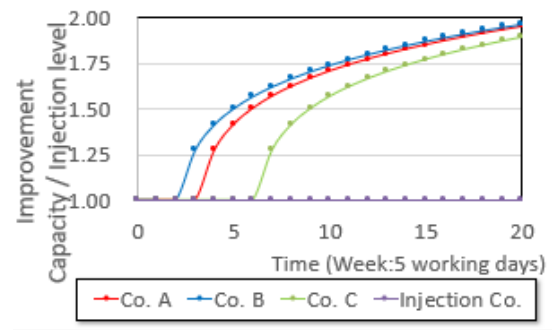

(a) Plan

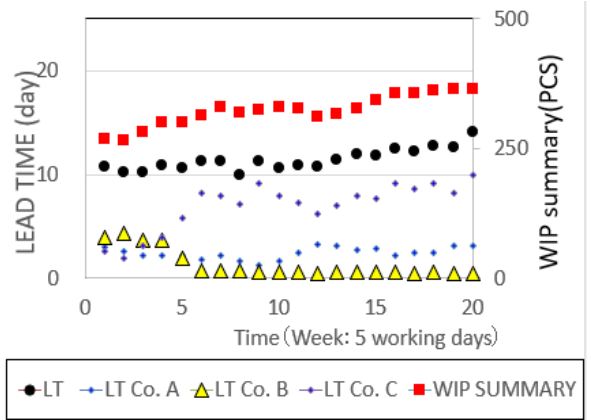

Figure 17. Simulation results (LT) at 1 company (Co. B) improving capacity.

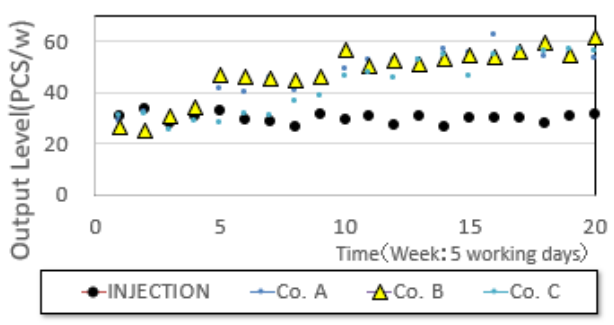

(b) Actual output

Figure 18. Scenario when each company (Co. A B) improving capacity with phase lug "Plan" \& "Actual output".

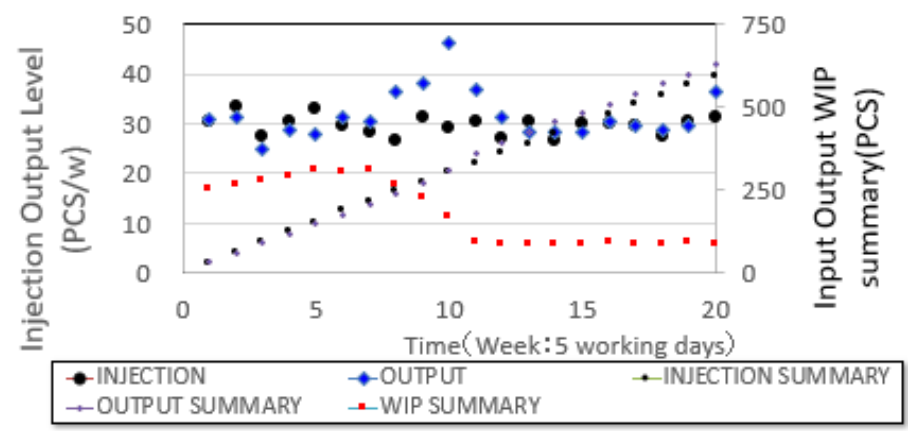

Figure 19. Simulation results (Input Output \& WIP in VC) when each company(Co. A B) improving capacity with phase lug.

Improvement on shortening LT shall reduce WIP in the system and increase cash (fast encashment), whenever company begin to improvement. It might be practical to find how much production capacity would be equipped. Increasing throughput must need increasing inlet. The question is to find production capacity proportion between inlet company output and each company in VC. VC has to increase input so that the production capacity proportion might be kept at steady index by continuous improvement on LT. 


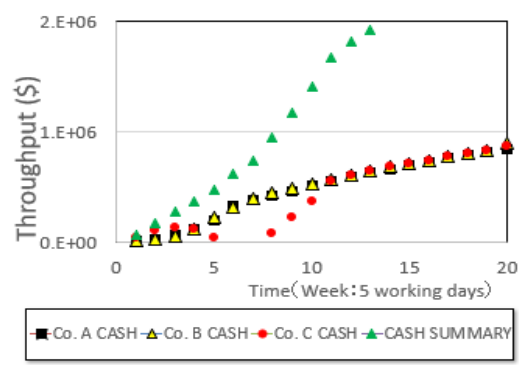

Figure 20. Simulation results (Throughpu(Cash)) when each company(Co. A B) improving capacity with phase lug.

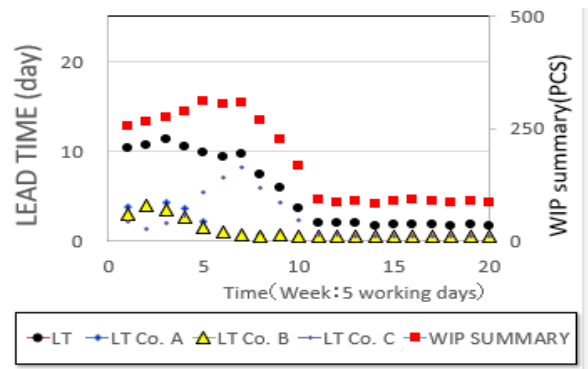

Figure 21. Simulation results (LT) when each company(Co. A B) improving capacity with phase lug.

Figure 22 shows the example of input increment control scheme. Inlet logic is to increase input with the half (50\%) of other company production capacity improvement. Figure 23-25 shows the simulation results and found that keeping production capacity buffer shall contribute to increasing profit of company continuously. Having production capacity buffer is quite important for company operation. For example, top management operate company with concept to have $20 \%$ production capacity buffer, and promote continuous improvement effort with evaluation on it, which operation cycle is effective.

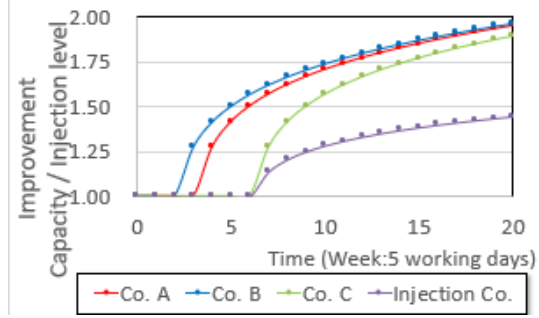

(a) Plan

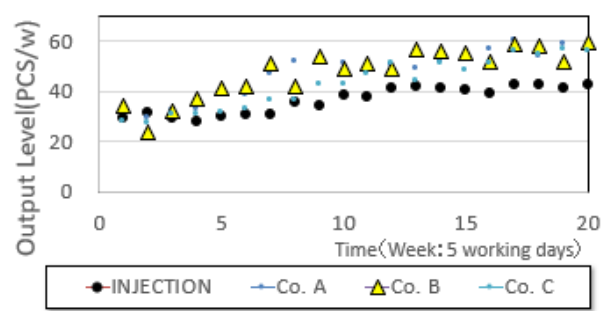

(b) Actual output

Figure 22. Improving scheme "Plan" \& "Aactual output".

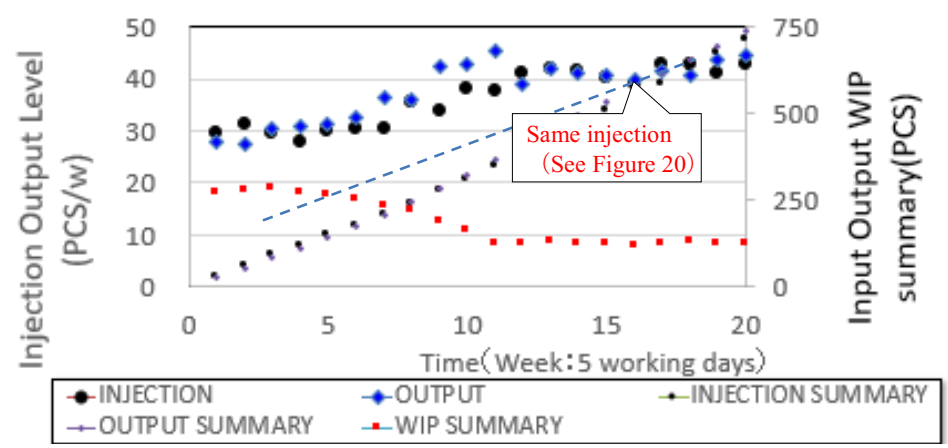

Figure 23. Simulation results (Input Output \& WIP in VC) by increasing injection with steady buffer capacity in Company in VC. 


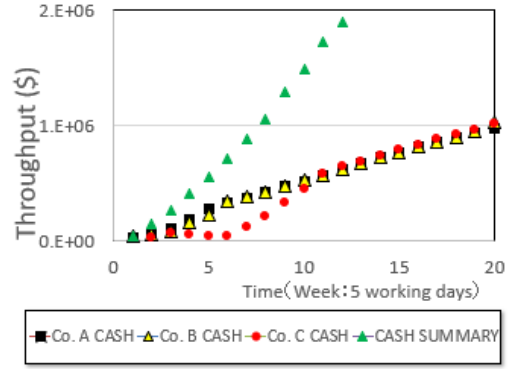

Figure 24. Simulation results (Throughput(Cash)) by increasing injection with steady buffer capacity in Company in VC.

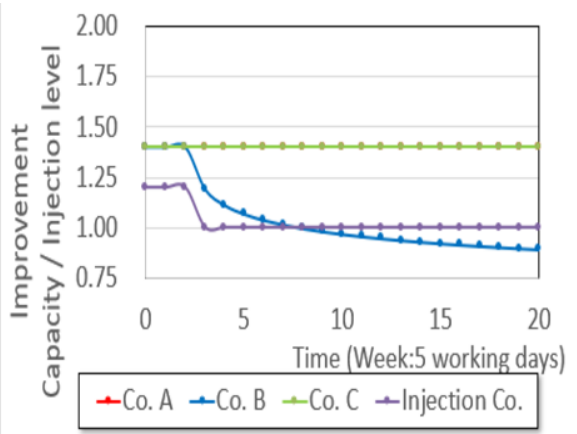

(a) Plan

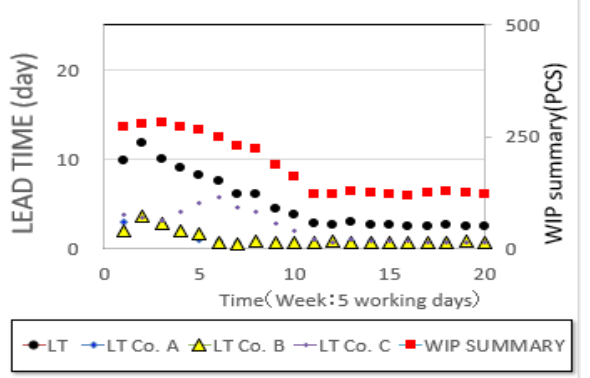

Figure 25. Simulation results (LT) by increasing injection with steady buffer capacity in Company in VC.

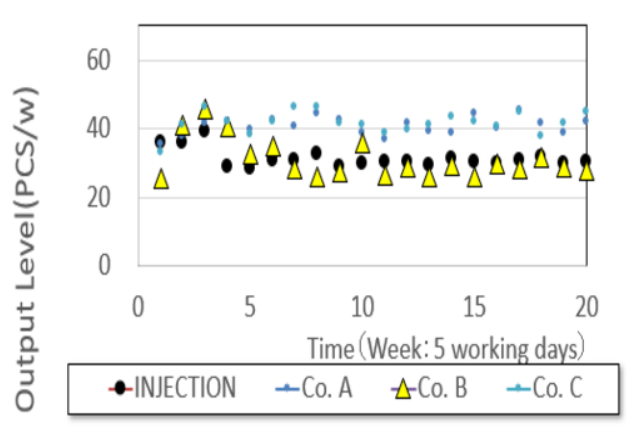

(b) Actual output

Figure 26. Co. B capacity decreasing scenario "Plan" \& "Actual output".

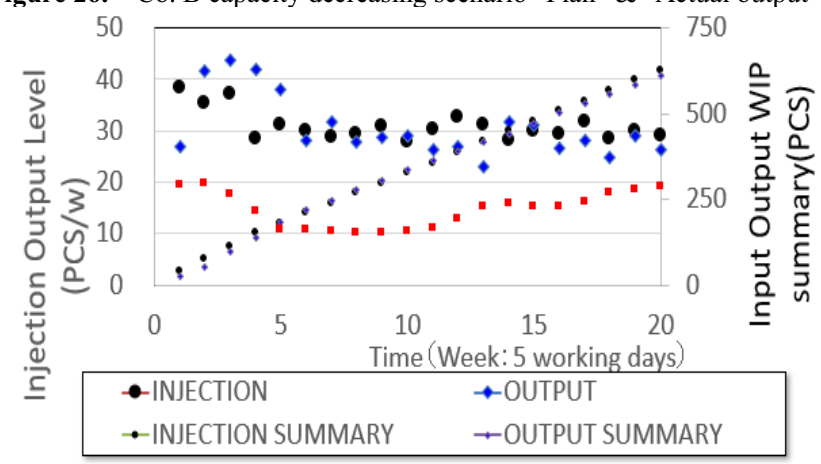

Figure 27. Simulation results (Input Output \& WIP in VC) by decreasing Co. B capacity.

Unexpected accidents are existed in the market. The occasion that 1(one) company in $\mathrm{VC}$ has to reduce its production capacity by some reasons. These scenario simulation is done. Figure 26-29 shows results. When 1 (one) company production capacity is less than inlet, WIP in the company shall be increased and throughput shall decrease due to increasing WIP. 


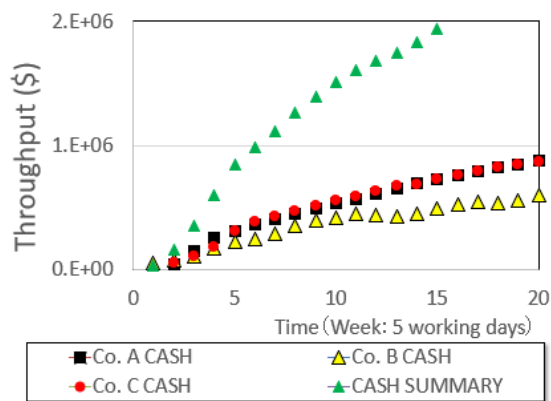

Figure 28. Simulation results (Throughput(Cash)) by decreasing Co. B capacity.

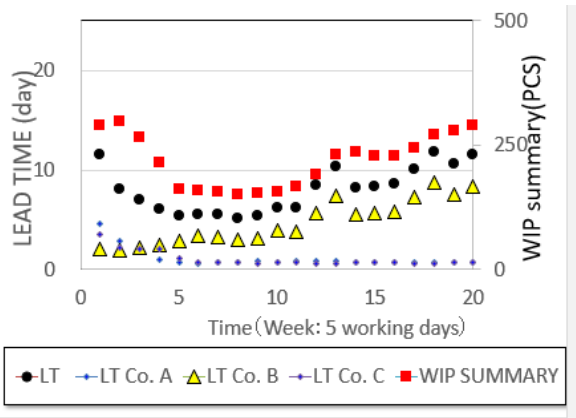

Figure 29. Simulation results (LT) by decreasing Co. B capacity

\section{Conclusion}

Reviewing the assumption to last company alive, the necessary management issue for continuing company were clarified by investigating how to keep steady working capital. The method and practical Index were obtained by dice simulations. Company can establish the steady condition of working capital by managing by Lead Time and steady capacity buffer as the vital power scale. The following conclusions were obtained.

1. It is necessary to improve Lead Time as management issue to keep steady working capital.

2. It is essential to have some margin on production capacity against inlet plan in order to have stable cash flow

3. Measuring production capacity buffer as the vital power scale is useful to evaluate company.

4. Improvement on production capacity shall bring better cash flow without effect to / by other companies in Value Chain.

5. Having production capacity with almost same inlet plan shall bring in stagnating Work In Process in system, which result in longer Lead Time than before. This condition shall increase risk to loose client in market.

\section{References}

[1] E.M. Goldratt, The Goal : A Process of Ongoing Improvement, Japanese edition, Diamond Co., 2001.

[2] E.M. Goldratt, The Goal 2 : It's Not Luck, Japanese edition, Diamond Co., 2002.

[3] E.M. Goldratt and J. Cox, The Goal, North River Press, Great Barrington, 1984.

[4] J. Cox, S. Bergland and D. Jacob, Velocity: Combining Lean, Six Sigma, and the Theory of Constraints to Achieve Breakthrough Performance, Free Press, New York, December 2009.

[5] E.M. Goldratt, The Heystack Syndrome:Shifting Information Out of the Data Ocean, Japanese edition, Diamond Co., 2005. 